PB97-195499

\title{
ASSIMILATION OF SATELLITE DATA IN REGIONAL AIR QUALITY
MODELS
}

\author{
Richard T. McNider, William B. Norris, and Daniel Casey \\ Earth Systeni Science Laboratory \\ University of Alabama in Huntsville \\ Huntsville, Alabama
}

Jonathan E. Pleim and Shawn J. Roselle

Atmospheric Science Modeling Division

Air Resources Laboratory

National Oceanic and Atmospheric Administration

Research Triangle Park, North Carolina

(on assignment to the National Exposure Research Laboratory, U.S. EPA)

William M. Lapenta

NASA Marshail Space Flight Center

Global Hydrology and Climate Center

Huntsville, Alabama

\section{INTRODUCTION}

In terms of important uncertainty in regional-scale air-pollution models, probably no other aspect ranks any higher than the current ability to specify clouds and soil moisture on the regional scale. Because clouds in models are highly parameterized, the ability of models to predict the correct spatial and radiative characteristics is highly suspect and subject to large error. While considerable advances have been made in the assimilation of winds and temperatures into regional models (Stauffer and Seaman, 1990), the poor representation of cloud fields from point measurements at National Weather Service stations and the almost total absence of surface moisturc availability observations has made assimilation of these variables difficult to impossible. Yet, the corrèct inclusion of clouds and surface moisture are of first-order importance in regional-scale photochemistry. Consider the following points relative to these variables.

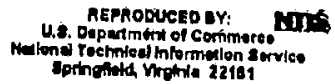


1. Clouds dominate the availability of actinic flux, which drives photochemical processes. Variations in cloudiness from clear to overcast change the available actinic flux below clouds by a factor of five or mcre. Yet, it is this actinic flux which directly affects the photolysis rates in photochemical models (Seinfeld, 1988; Dunker, 1980). Thus, inaccurate specification of the photolysis rates either in terms of mean bias or in the correct time and space specification can in a first-order fashion affect model performance.

2. On a regional scale clouds are the prime controller of surface temperature through their $15^{\circ} \mathrm{F}$ and solar insolation. Variations in cloudiness can alter air surface temperatures by 10 $15^{\circ} \mathrm{F}$ and surface skin temperatures by $30^{\circ} \mathrm{F}$ or more. Given that biogenic isoprene temperature (Tingey et al. 1979. Zimissions are highly nonlinearly dependent upon surface their distribution can drastically change the chemin et al., 1988), then errors in mean clouds or reasonably conclude that the current emphasis on of the environment. In fact, one could emissions morels has gone beyond eur ability on improved spatial and temporal biogenic accuracy.

3. Surface moisture availability is probably second only to clouds in controlling surface temperature (Wetzel et ai., 1984; Carlson et al., 1981; Pleim and Xiu, 1995). Moist surfaces or actively transpiring vegetation can sharply reduce temperatures over that of dry surfaces. Thus, regional mean temperatures and spatial variations in temperature are dependent on the specification of moisture. In the past, surface moisture availability in the absence of observations has sometimes been used as a tuning device. However, given the high inhomogeneity in moisture availability this can lead to spatial errors and mean bias feeding
back into the emission errors discussed above.

4. Mixing heights in regional-scale models, which affect pollution and precursor concentrations in a direct, inverse-linear way, are highly dependent un surface temperature through the surface sensible heat flux (Deardorff, 1974). This surface heat flux is in turn controlled by insolation and surface moisture availability. Thus, errors in specification of clouds and surface moisture can substantially alter air-pollution concentrations. In addition, cumulus cloud convection can effectively deepen the mixing height to include a large portion of the troposphere, drastically altering boundary-layer concentrations, and can inject precursors into an environment where the chenistry can be quite efficient and chemical chain
lengths long in the absence of surface losses.

In summary, the above discussion shows the importance of clouds and surface moisture availability in regional models. While considerable emphasis has been placed on wind direction in regional scale models, the winds affect the distribution of pollutants but clouds and moisture availability highly affect the photochemical production. (The clouds and moisture also affect winds--see below). The domino effect of clouds and moisture through photolysis rates, emissions, mixing heights, etc., makes them a pivotal element in regional
models.

It is the purpose of this paper to describe methods of satellite remote sensing that can be used to specify clouds and surface moisture in photochemical models with improved fidelity on the regional scale. Specifically, geostationary data is used because of the temporal and spatial coverage available. The following summarizes techniques for estimating insolation,
photolysis rates, and surface moisture.

\section{INSOLATION}

The net solar radiation at the surface provides the prime source of encrgy controlling the diurnal variation in temperature in the surface energy budget in regional scale models. In 
addition to astronomical factors, the net radiation at the surface is determined by the surface albedo, reflection, and absorption of solar radiation by the the clear atmosphere and the reflection and äbsorption by the cloudy atmosphere (including aerosols).

\section{Surfacé Albedo}

The surface albedo in regional-scale models such as MM5 (Grell et al., 1994) or RAMS (Pielke, 1992) is usually estimated using land-use types. However, the relationship between gross land-use characteristics and its radiative properties is not always well defined. Additionally, the albedo can change due to meteorological conditions and anthropogenic changes (such a harvesting) which are not included in routine land-use data bases. Satellites on the other hand, provide a direct radiative measurement of reflected radiation, although interpretation due to view angle and bi-directional effects must be considered (Gautier et al.,
1980 ).

The geostationary series of satellites (GOES) operated by NOAA in the U.S. over the last two decades provide satellite coverage over the U.S. that can be used in regional models. In 1995 a new version of geostationary satellites beginning with GOES-8 was launched with different characteristics than previous GOES (i.e., GOES 7 and earlier). The GOES-7 (GOES-8) satellite retums the magnitur. of upwelling radiance in the visible as brightness counts in the range 0-63 (0-1023). The lowest counts arise when little or no cloud is present and the reflection is primarily, if not entirely, from the earth's surface. Using the physical retrieval method of Gautier êt al. (1980) and Diak and Gautier (1983), the surface albedos can be recovered from the brightness counts retumed by GOES satellites. The technique requires hourly surface albedos obtained from clear-sky brightness counts. If a single, cloudfree image were available for each hour of daylight, the brightness counts could be obtained directly from them. However, because cloudy skies are so common, a single, cloud-free image is usually not aväilable. Experience has shown that for a given daylight hour images over a period of 20-30 days are needed to obtain a stable minimum brightness count for that hour, especially in the Southeast during summer when cumulus clouds are ubiquitous. Brightness counts are converted into reflectances using a calibration curve unique to each satellite. This approäch has the inherent ability to account for both spatial and temporal differences in albedo due to soil type, vegetation, and time of day and year. Figure 1 shows a clear-sky albedo derived using this technique and converted to an $80 \mathrm{~km}$ grid used in MMS.

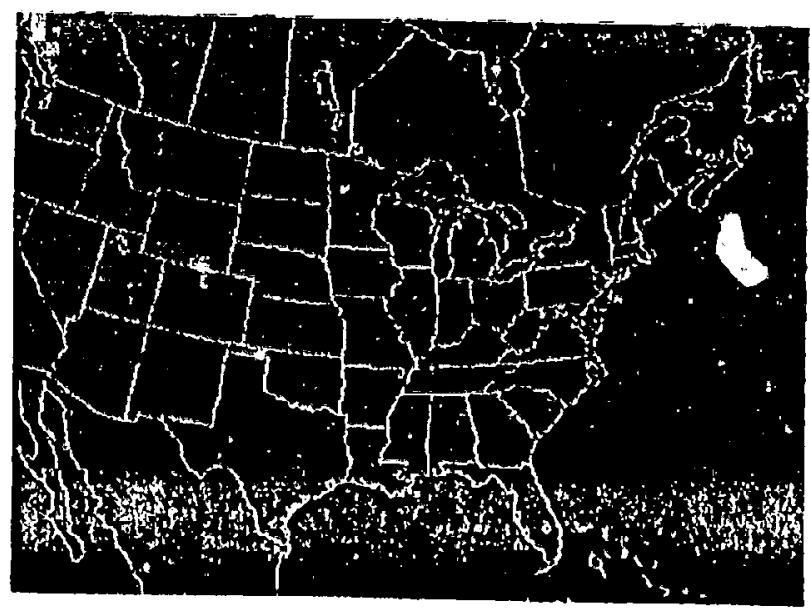

Figurie 1. Clear- sky albedo using minimum brightness from GÖES-7 images du-ing July 1988 gridded to
an 80-kin MM5 domain. 


\section{Cloud Albedo}

Once the clear-sky albedo and the brightness count are known for a given satellite-image pixel, surface insolation at the pixel level (usually 1,4 , or $8 \mathrm{~km}$ ) can be calculated from the simplified radiative-transfer model of Gautier et al. (1980) as described in McNider et al. (1995). The model assumes a single cloud layer. Above the cloud layer, radiation is Rayleigh scattered and absorbed by water vapor. In the cloud layer, radiation is scattered and absorbed. Below the cloud layer, radiation is absorbed by water vapor. For the scattering coefficients, we use the parameterization originally presented by Kondratyev (1969) and modified by Atwater and Brown (1974). For the water-vapor absorption coefficients, we use an empirical formulation of MacDonald (1960). For in-cloud absorption we use a step function that depends on brightness count (McNider et al., 1995). This results in a quadratic equation in cloud albedo. Once knorrn the cloud albedo can be used to calculate downwelling
solar radiation and insolation at the surface.

A flow chart of the computational procedure is shown in Figure 2. The procedure yields surface insolation at each pixel in an image. Such images can be gridded and values fur all pixels within a grid cell averaged to produce hourly input fields for assimilation into photochemical models or meteorological models. Figure 3 shows the surface insolations computed by this technique for Julian day 216 on an $80-\mathrm{km}$ MM5 grid covering most of the U.S.

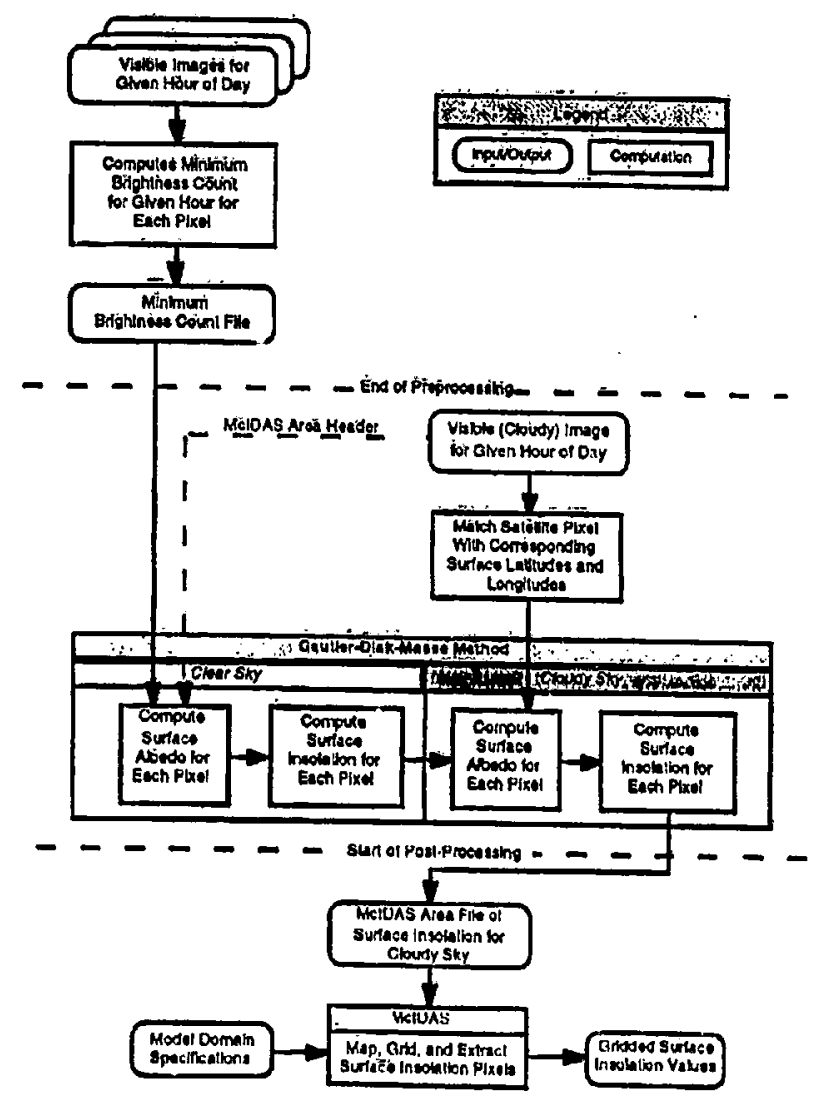

Figure 2. Flow chart of computational procedures for determining surface insolation. 


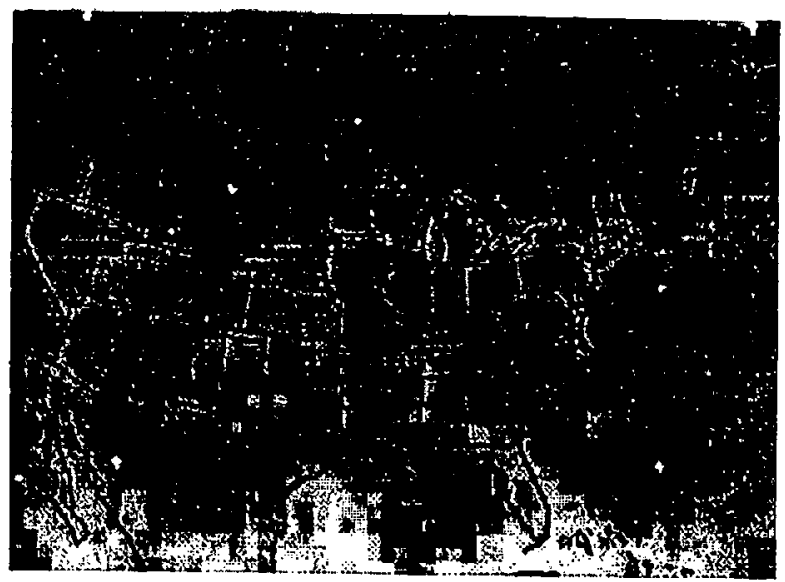

Figure 3. Surface insolation computed from a satellite imiage for an 80-km grid for 1800 GMT Julian Day 2161988.

While the GOES visible sensors do not have on-board calibration, prelaunch calibration curves (Raphael and Hay, 1984) and ground-truth data (Tarpley, 1979) can approximate the needed calibration information. To provide some understanding of the fidelity of the technique a comparison of observed versus satellite derived insolation value for the period July 31-August 7, 1988 was made. Observed data were taken from available surface pyranometer archives (National Renewable Energy Laboratory, 1992). Becáuse the GOES sensor measures a near instantaneous value of clouds and the pyranometer data are hourly averages exact agreement cannot be expected. Additionally, the absolute navigation of the GOES-7 image is of order $10 \mathrm{~km}$. Thus, in making the comparison between the satellite data and pyranometer data the best-fit satellite pixel value within $20 \mathrm{~km}$ of the pyranometer site was utilized. Figure 4 shows this comparison. While scatter exists, the key fact is that the calibration data used shows almost no bias in the insolation values. Because the insolation calculations are based on rather straightforward radiative principals and insolation is fairly insensitive to uncertain specifications such as cloud absorption (McNider et al., 1995), it is felt that absolute and especially the relative spatial accuracy is quite high.

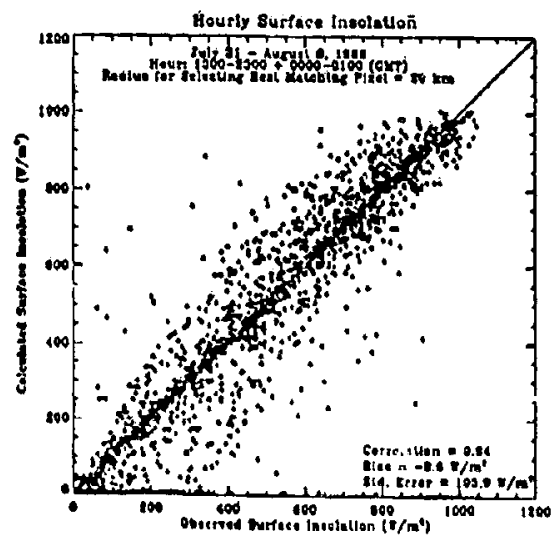

Figure 4. Comparison between satellite-derived and surface pyranometer-measured insolation valucs for the period July 31-August 8, 1988. The best-fit pixel was used within a 20-km radius of the observation site. 


\section{PHOTOLYSIS RATES}

Photochemical modeling systems differ in their sources of photodissociation constants. In some cases these are obtained from radiative transfer models that include the scattering, absorbing, or reflecting properties of atmospheric aerosols and clouds (e.g., Ruggaber et al., 1994; Rosselle et al., 1995). In other cases radiative transfer models assume clear skies, and correction factors are later applied to the results to obtain the desired cloudy-sky values (e.g., Chang et al., 1987). In either approach cloud information is essential.

In order to compute cloud effects on photólysis rates three fundamental parameters are needed: (1) cloud-layer transmittance, (2) cloud-top elevation, and (3) cloud-layer bottom elevation. In the past in photochemical models these parameters were estimated based on hydrological information from the meteorological processor. Often the information used to recover these parameters is fairly indirect. For example, RADM approximates the cloud optical depth $\tau$ with the parameterization

$$
\tau=3 L_{\text {con }} \Delta z_{c l d} / 2 \rho_{H_{2}} \mathrm{Or}
$$

where $L_{c o n}$ is the mean condensed water content, $\Delta z_{c l d}$ is the mean depth of the cloud layer, $r$ is the mean cloud drop radius, and $\rho_{\mathrm{H}_{2} \mathrm{O}}$ is the density of water (Chang $e t$ al., 1987). In $\mathrm{RADM}$, constant values are assumed for each factor except $\Delta z_{c l d}$, which is obtained from the meteorological model. This cloud optical depth is then used in a Beer's Law type of formulation to estimate cloud transmittance. In practice the cloud top is often determined from relative humidity thresholds and cloud base from computed lifting condensation levels. We now propose techniques that use satellite data to estimate two of the needed parameters-cloud transmittance and cloud-top elevations and discuss options for determining cloud base.

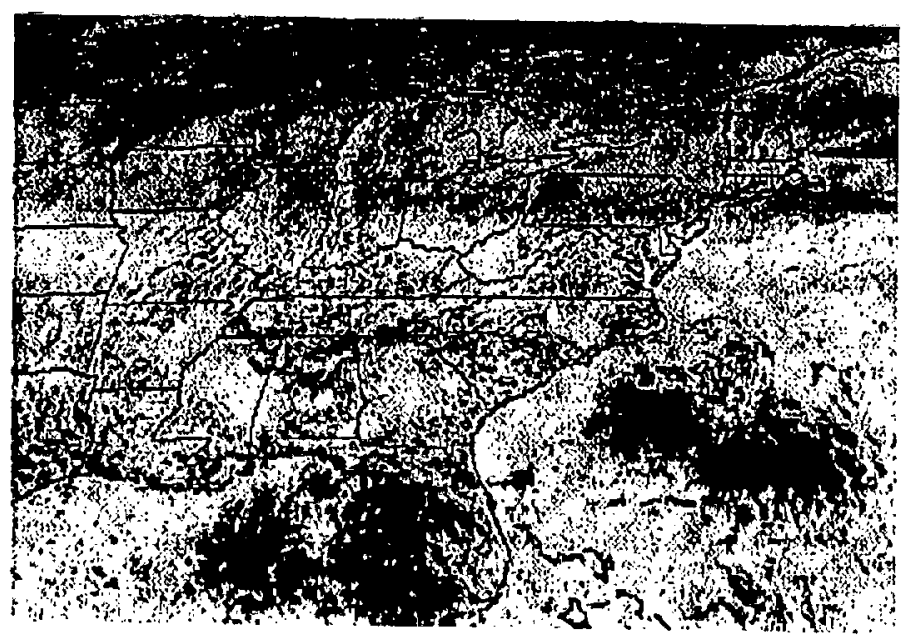

Figure 5. Satellite-derived transmittance field for 1800 GMT Julian Day 2161988.

\section{Satc̈llite-Derived Transmittance}

Clond transmittance is fundamentally a radiative property and can be recovered from the requirement that cloud transmittance, reflection and absorption sum to unity. We make the assumption that the broad-band transmittance determined from the satellite sensor $(0: 52$. $0.72 \mu \mathrm{m})$ is the approximate transmittance required in the ultimate photolysis calculations. 
Since cloud reflectance is determined above in the insolation step and if the same absorptivity function is used then cloud transmittance can be computed. Absorptivity is the least well known parameter in the present scheme. McNider et al. (1995) showed in sensitivity test's that even making extreme changes in the absorptivity function changes the tranmittance only slightly. Figure 5 shows the transmittance field determined by satellite for a RADM $80-\mathrm{km}$ grid using these techniques described above.

\section{Satellite-Derived Cloud-Top Elevations}

Cloud-top elevations can be èstimated using infrared satellite images from atmospheric clear-window channels. Just as with visible images, GOES-8 returns infrared measurements in discrete counts in the range 0-1023. These values correspond to blackbody temperatures and in clear-window channels represent the temperature of the Earth's surface in clear regions and cloud-top temperatures in cloudy' regions. If a temperature sounding is available near the location of a pixel at the time of the satellite measurement, the pressure level, and hence the elevation, at cloud top can be determined. At this point in the development of the technique, for a given pixel we are using the grid point sounding from the meteotological model. Figure 6 shows satellite-derived cloud top elevations.

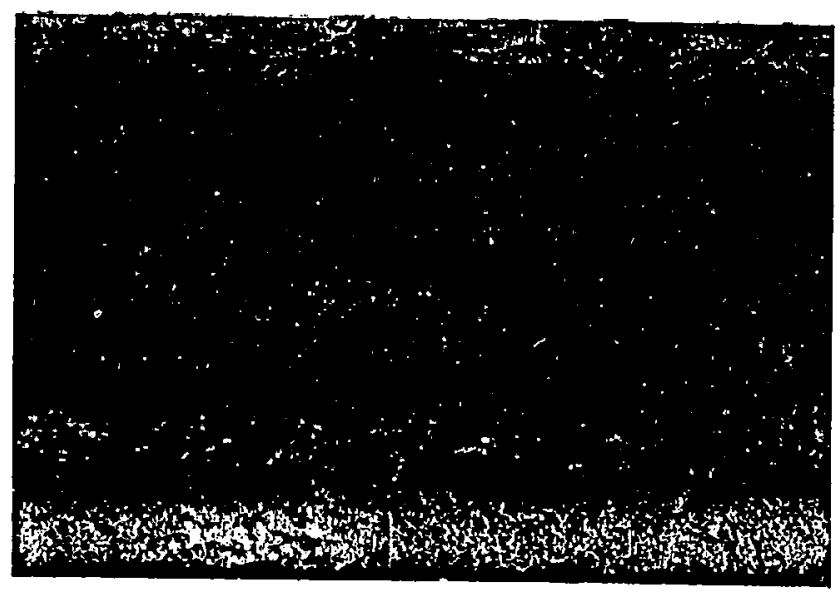

Figure 6. Satellite-derived cloud-top elevations for 1800 GMT Julian Day 2161988.

\section{Cloud-Bàse Ẽlevations}

GOES satellites cannot provide any guidance on the cloud base since infrared techniques cannot determine the depth of clouds. However, auxiliary thermodynamic structure information can be used to compute the lifting condensation level (LCL) which gives a lower limit on the cloud-base elevation. This auxiliary information can come from prognostic mesoscale models or rawinsonde observations.

\section{Satèllite-Derived Photolysis Fields}

The cloud characteristics defined above were utilized in a photolysis model inec porated in a new version of the RADM regional photochemical model. Figures 7 and 8 show a comparison between the photolysis fields generated from the satellite-derived cloud characteristics and the diagnostic determination of cloud characteristics from the prognostic meteorological model ficlds. The differences are quite dramatic for this hour, with the 
diagnostic models overestimating cloud coverage. Analysis of this case is continuing, but it perhaps points to a major problem in that the highly parameterized cloud characteristics may not be capturing the actual cloud fields with fidelity.

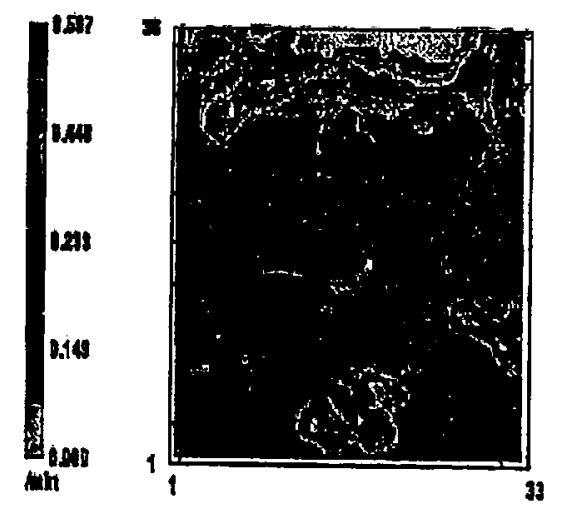

Figure 7. Satellite-derived photolysis fields $\left(\mathrm{J}_{\mathrm{NO} 2}\right) 1800$ GMT Julian Day 216, 1988.

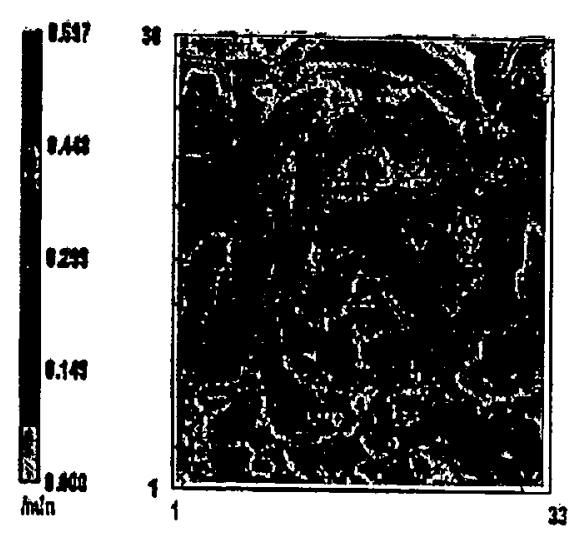

Figure 8. Photolysis fields $\left(J_{\mathrm{NO} 2}\right)$ derived from prognostic model output 1800 GMT Jutian Day 2161988.

\section{SURFACE MOIST'URE AVAILABILITY}

As mentioned in the introduction, biogenic and soil $\mathrm{NO}_{x}$ emissions rates highly depend on surface temperature. Mixing heights and turbulent dispersion characteristics are also dependent upon surface temperatures. Surface temperatures are highly sensitive to specification of surface moisture (Pleim and Xiu, 1995), yet moisture is not readily available as an observable and must be estimated using vegetation and soil moisture parameterizations that contäin difficult-to-specify parameters such as deep root-zone moisture, stomatal conductance. To avoid these problems we have developed a method employing infrared satellite images that is capable of assimilating satellite-observed surface temperature rates of change into boundary-layer models in a thermodynamically consistent manner that recovers soil moisture. The technique requires the use of GOES-8 derived infrared images, land surface temperatures (LSTs), surface albedo, and insolation over the time period of interest. It is based upon adjusting the model's bulk moisture ayailability so that the model's rate of change of LST agrees more closely with the "observed" rate of change of LST as derived 
from the satellite. A critical assumption is that the availability of moisture (either from the soil or vegetation) during mid-morning hours is the least known term in the model's surface energy budget (Wetzel et al., 1984; Carlson 1986). Therefore, the simulated latent heat flux, which is a function of surface moisture availability, is adjusted based upon differences between the modeled and satellite-derived LST tendencies.

Here we present results from the assimilation techrique as applied within MMS for 7 July 1995 using a grid resolution of $12 \mathrm{~km}$. The region of interest was over Oklahoma and Kansas where a west-east vegetation gradient existed (wheat stubble to the west, deciduous forest to the east). Given this variation ir vegetation, one would expect the satellite-observed surface thermal response to differ across the region. The LST is derived via a physical split window technique (Guillory et al., 1993) from GOES 8 data from 1200 to 2300 UTC on 7 July 1995. The LST tendencies are fairly uniform actoss the region from 1200 to 1400 UTC. However, between 1400 and 1700 UTC the LST tendency in eastern Oklahoma $\left(5^{\circ} \mathrm{C}\right.$ per $3 \mathrm{~h}$ ) is considerably lower than that farther west $\left(10^{\circ} \mathrm{C}\right.$ per $3 \mathrm{~h}$ ). This spatial variation is consistent with the west-east vegetation gradient that existed across the region.

The assimilation scheme in MM5 adjusts the evaporative flux by altering the moisture availability parameter, $M$, which represents the fraction of possible evaporation for a saturated surface. When the standard procedure of specifying $M$ as a function of land-use category was used to initialize the model, the field exhibits an unrealistic, blocky structure (Figure 9, left panel).

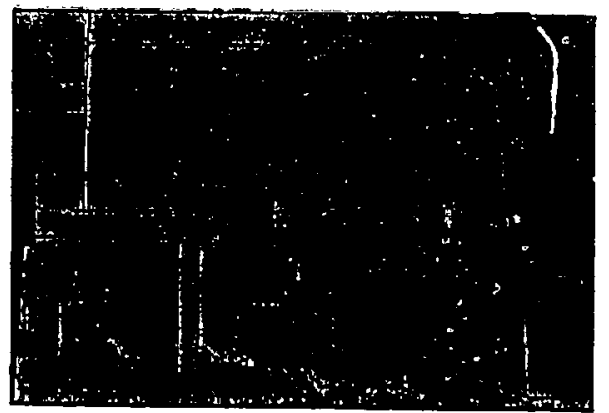

TMITAL (IASED ON TANO UEE)

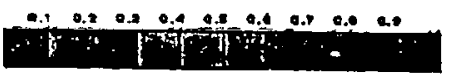

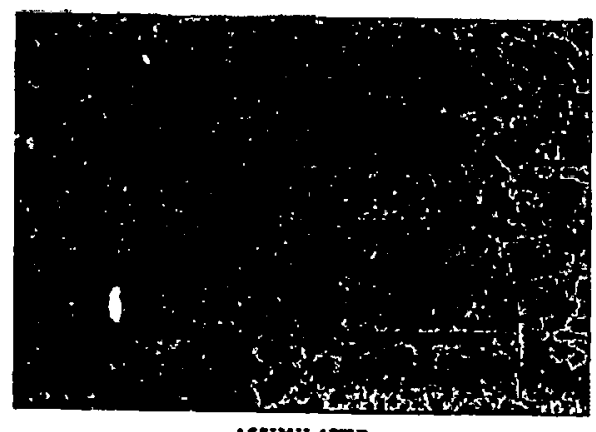

AsstMILATED

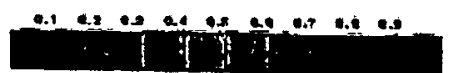

Figure 9. Model moisture availability, $M$, representing the fraction of possible evaporation for a saturated surface. The left panel (a) shows the moisture availability based upon land-use categories while the right panel (b) displays it after assimilating GOES data.

After assimilating GOES LST tendencies from 1400 UTC to 1800 UTC (900 to 1300 local standard time), the adjusted $M$ exhibits a more realistic structure (Figure 9 , right panel) which matched well with Normalized Difference Vegetation Index (NDVI) (not shown). A more stringent check of the technique was done by comparing modeled surface evaporative flux data from observations obtained via Energy Balance Bowen Ratio (EBBR) systems deployed at the Southern Great Plains (SGP) Cloud and Radiation Testbed (CART) sites for the U.S. Department of Energy's Atmospheric Radiation (ARM) Program (Splitt et al., 1995). Without the assimilation, MMS greatly overestimates the daytime evaporative flux by $300 \mathrm{Wm}^{-2}(150 \%)$ on both 7 and $8 \mathrm{July}$. However, use of the satellite data produces a much more realistic time series with an average difference for the $36 \mathrm{~h}$ period of less than $40 \mathrm{Wm}^{-2}$. 


\section{REFERENCES}

Atwater, M. A. and P. S. Brown, Jr, 1974, Numérical calculation of the latitudinal variation of solar radiation for an atmosphere of varying opacity, J. Appl. Meteor., 13:289-297.

Carison, T. N., 1986, Regional scale estimates of surface moisture availability and therthal inertia using remote thermal measurements. Remote Sensing Rev., 1:197-246.

Carlson, T. N., J. K. Dodd, S. G. Benjamin, and J. N. Coojper, 1981, Satellite estimation of the surface energy balance, moisture availability and thermal inertia, J. Appl. Meteor., 20:67-87.

Chang, J. S., R. A. Brost, I. S. A. Isaksen, S. Madronich, P. Middleton, W. R. Stockwell, and C. J. Walcek, 1987, A three-dimensional eulerian acid deposition model: physical concepts and formulation,
J. Geophys. Res., 92:D12, 14681-14700.

Deardorff, J.,1974, Three-dimensional numerical study of the height and mean structure of the planetary boundary layer, Bound-layer Meteor. 15:1241-1251.

Diak, G. R. and C. Gautier, 1983, Improvements to a simple physical model for estimating insolation from GOES data, J. Appl. Mnieor., 22:505-508.

Dunker, A. M., 1980, The res punse of an atmospheric re/action-transport model to changes in input function, Atmos. Environ., 14:671-679.

Gaulier, C., G. Diak, and S. Masse, 1980, A siripite physical mojel to estimate incident solar radiation at the surface from GOES satellite data, J. Appl. Meteor., 19:1005-1012.

Grell, G. A., J. Dudhia, and D. R. Stauffer, 1994, A Description of the Fifth-Genteration Penin StateNCAR Mesoscale Model (MM5). NCAR Tecinnical Note NCAR/IN-398+STR, Nationial Center for Atmospheric Research, Boulder, Colorado.

Guillory, A. R., G. J. Jedlovec, and H. E. Fuelberg, 1993, A technique for deriving column-integrated water content using VAS split-window data, J. Appl. Meteor., 32:1226-1241.

Kondratyev, K. Y., 1969, Radiation in the Atmosphere., Academic Press, New York.

McDonaid, J. E., 1960, Direct absorption of solar radiation by atmospheric water vapor, J. of Meteor., 17:319-328.

MeNider, R. T., J. A. Song, and S. Q. Kidder, 199S, Assimilation of GOES-derived solar insolation into a mesoscale model for studies of cloud shading effects, Int. J. Remote Serhsing, 16:2207-2231.

National Renewäble Energy Laboratory, 1992, National Solar Radiation Data Base User's Mantual (1961. 1990), Golden, Colorado.

Pièlke R. A., W. R. Cotton, R. L. Walko, C. J. Tremback, W. A. Lyons, L. D. Grasso, M. E. Nicholls, M. D. Moran, D. A. Wesley, T. J. Lee, and J. H. Copeland, 1992, A compreheriseive meteorological modeling system--RAMS, Meteor. Atmos. Phys., 49:69-91.

Pleim, J. E. and A. Xiu, 1995, Develópment and teśting of a surface flux and planetary boundary layer model for application in mesoscale models. J. Appl. Meteor., 34:16-32.

Raphael, C., and Hay, J. E., 1984, An assessment of models which use satellite dta to estimate solar irradiance at the earth's surface, J. Climate and Appl. Meteor., 23:832-844.

Roselle,S. J., A. F. Hanna, Y. Lu, J. C. Jang, K. L. Schere, J. E. Pleim, 1995, Réfined photolysis rates for advanced air quality modeling systems, in Proceedings of the A\&WMA Conference on the Applications of Air Pollution Meteorology.

Ruggaber, A., R. Dlugi, and T. Nakajima, 1994, Modelling radiation quantities and photolysis frequencies in the troposphere, J. Atmos. Chem., 18:171-210.

Seinfeld, J. H., 1988, Ozone Air Quality Models: A critical review, J. Air Poll. Control Assoc, 38:616645.

Splitt, M. E. and D. L. Sisterson, 1995, Site Scientific Misssion Plan for the Southern Great Plains CART Site: July-December 1995, ARMM:95-002, Argonne National Laboratory, Argonne, Illinois.

Stauffer, D. R. and N. L. Seaman, 1990, Use of four-dimensional data assimilation in a liñited-area mesoscale model. Part I: Experiments with synoptic-scale data, Mon. Wea. Rev., 118:1250-1277.

Tarpley, J. D., 1979, Estimating incident solar radiation at the surface from geostationary satellite data, J. of Appl. Meteor., 18:1172-1181.

Tingey, D. T., M. Manning, L. C. Grothaus, and W. F. Burns, 1979, The influence of light and temperature on isoprene emission rates from live oak, Physiol. Plant, 47:112-118.

Wetzcl, P. J., 1984, Determining soil moisture from geosynchronous satelite infrared data: A feasibility study, J. Climaie Appl. Metcor., 23:375-391.

Zimmerman, P. R., J. P. Greenberg, and C. E. Westberg, 1988, Mcasurements of atmospheric hydrocarbons and biogenic emission fluxes in the Amazon boundary laycr, $J$ : Geophys. Res., 93:1407-1416. 


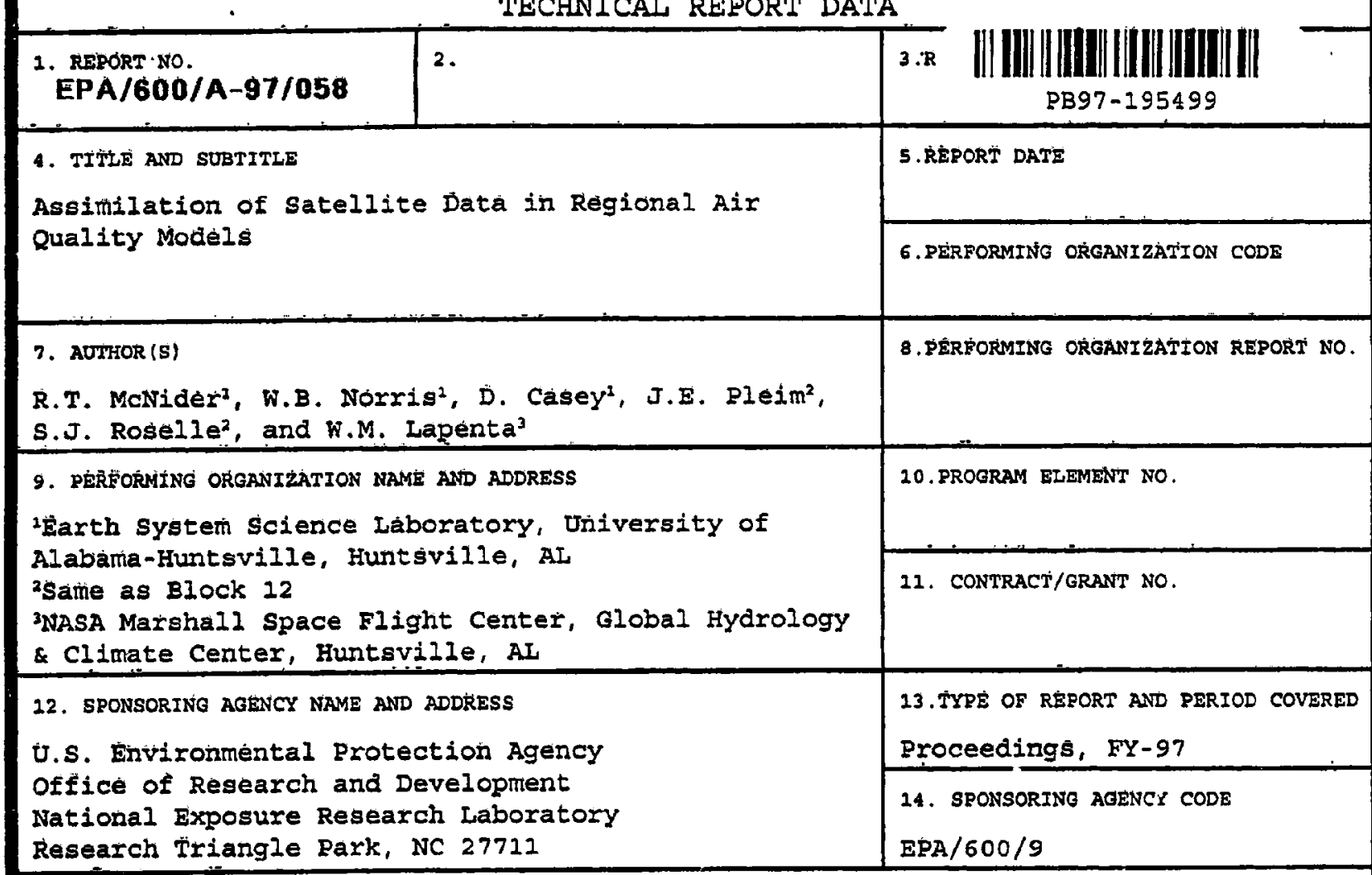

15. SUPPLEMENTARY NOTES

\section{ABSTRACT}

In terms of important uncertainty in regional-scale air-pollution models, probably no other aspect ranks any higher than the current ability to specify clouds and soil moisture on the regional scale. Because clouds in models are high'y parameterized, the ablitity of models to predict the correct spatial and radiative characteristics is highly suspect and subject to large error. While considerable advances have been made in the assimilation of winds and temperatures into regional models (Stauffer and seaman, 1990), the poor representation of cloud fields from point measurements at vational Weather service stations and the almost total absence of surface moisture availability observations has made assimilation of these variables difficult to impossible. Yet, the correct inclusion of clouds and surface moisture are of first-order importance in regional-scale photochemistry.

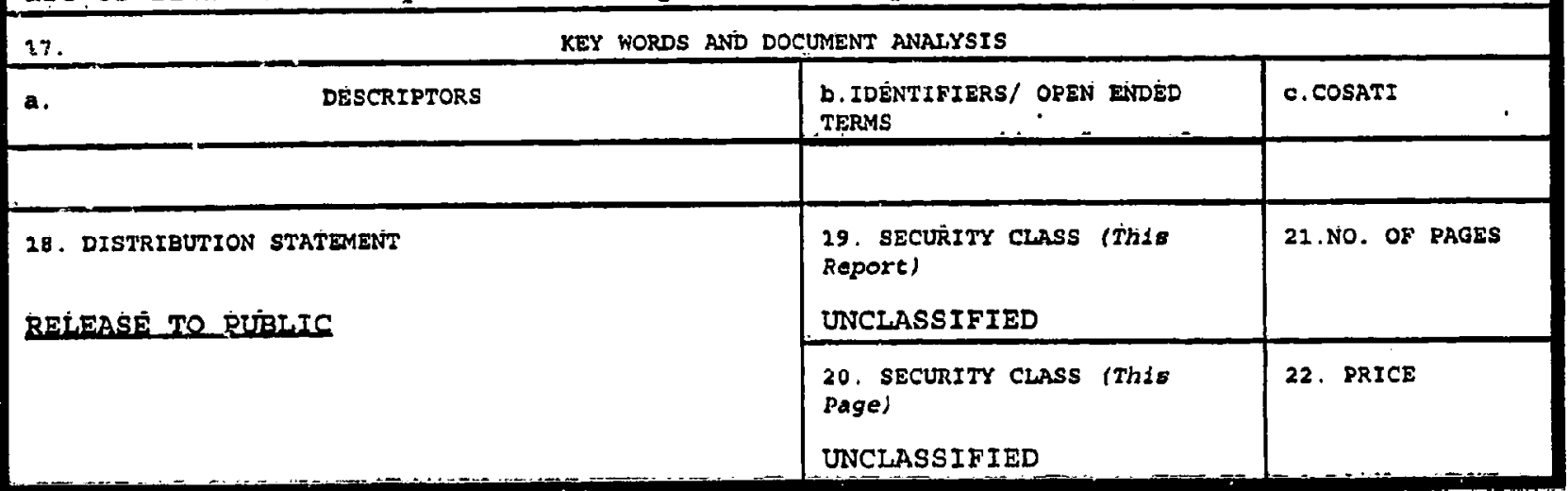





\title{
Reproduced by NTIS
}

\author{
National Technical Information Service \\ Springfield, VA 22161
}

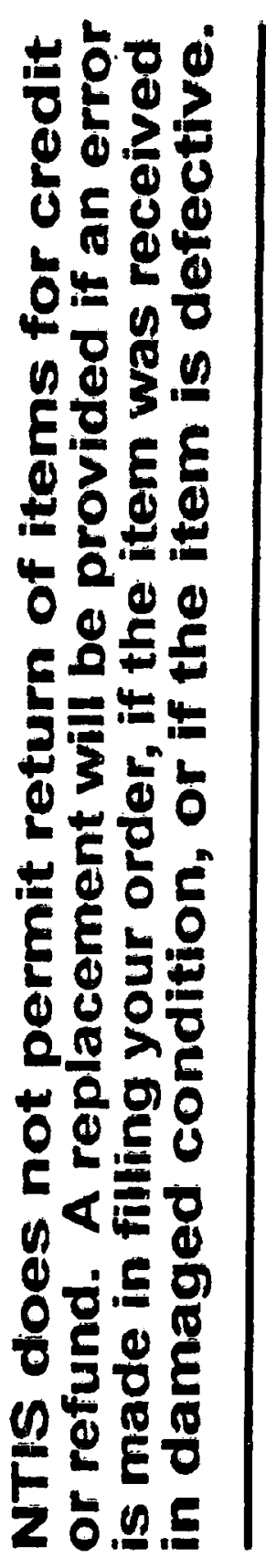

\author{
This repori was printed specifically for your order \\ from nearly 3 million titles available in our collection.
}

Fot economy and efficiency. NTIS does not maintain stock of its vast collection of technical repoits. Rather, most documents are printed for each order. Documents that are not in electronic format are reproduced from master archival copies and afe the best possible reproductions available. If you have any questions concerning this document or any order you have placed with NTIS, please call our Customer Service Department at (703) 487-4660.

\begin{abstract}
About NTIS
NTIS collects scientific, technical, engineering, and business related information - then organizes, maintains, and disseminates that information in a variety of formats - from microfiche to online services. The NTIS collection of nearly 3 million titles includes reports describing research conducted or sponsored by federal agencies and their contractors; statistical and business information; U.S. military publications; audiovisual products; computer software and electronic databases developed by federal agencies; training tools; and technical reports prepared by research organizations worldwide. Approximately 100,000 new titles are added and indexed into the NTIS collection annually.
\end{abstract}

For more information about NTIS products and services, call NTIS at (703) $487-4650$ and request the free NTIS Catalog of Products and Services, PR-827LPG, or visit the NTIS Web site http://Wunw.ntis.gov.

\section{NTIS}

Your indispensable resource for government-sponsored information-U.S. and worldwide 